that, although international co-operation is compatible with secrecy regulations only under exceptional conditions, in normal times the temptation to secrecy can be kept within reasonable bounds and channels of information kept open. Of the opportunities for co-operation, he lists first studies on high-flux reactors, followed by the application of electronic computation to reactor technology. Reactor physics also offers considerable possibilities, particularly through the pooling of material resources, as does the conversion of fission-generated heat into electric power. Besides the advanced types of power reactors, research on materials and components, research on miscellaneous applications of nuclear energy whether in medical or biological research, the sterilizing irradiation of food or other utilization of by-products, and problems of the disposal of waste materials offer important opportunities. The concrete suggestions for co-operation made in this report are, first, the creation of an 'Advanced Proposals Committee', to scrutinize new trends and ideas in this field, together with study groups on the direct conversion of nuclear energy to electric power and on data processing. Authoritative discussions could also be initiated into possibilities of co-operation on fluid-fuel and heavywater reactors, making full use of the potentialities which already exist at Oak Ridge, particularly in the molten-salts reactor.

\section{The Frederick Soddy Trust}

The report of the Frederick Soddy Trust (dated September 1958. Pp. 16. (Hove, Sussex: The Frederick Soddy Trust, 9 The Drive)), gives some indication of the principles to be employed in selecting projects for support, and these are further emphasized by the list of rejected applications by August 1957 and the record of grants made up to September 1958 which are included in the report. One further application, a large-scale and ambitious project for studies in a Central American desert, was rejected because it required support on a much larger scale than the Trust was able to give. On the principles themselves, the report emphasizes that team work rather than individual work is to be supported; other things being equal, preference is to be given to original work leading to some published report, and the emphasis throughout must be on actual study and research in the field. Grants will normally only be made to persons reasonably qualified to carry out the work and, if possible, where the study is being carried out under competent and qualified leadership. Special value is to be attached to organized co-operation with local workers when field studies in a foreign country are undertaken. Some details are included of the programme of crofting field studies, 1957; the proposed study of Corby and the proposed survey of the parish of Ardington, Berkshire, by the University of Reading; and of a proposed expedition to the Pyrenees.

\section{Australian Rock Art}

ONCE again students of primitive native art have to thank Mr. F. D. McCarthy, who has recently published two articles in the Records of the Australian Museum. One deals with the rock-shelter paintings of the Conjola District in New South Wales (24, No. 13; March 9, 1959: "Cave Art of the Conjola District, New South Wales". Pp. 191-202 + plate 22. Sydney: The Australian Museum); the other with certain rock engravings from the Sydney-Hawkes. bury District (24, No. 14; March 9, 1959: "Rock Engravings of the Sydney-Hawkesbury District". Sydney: The Australian Museum). In both cases, conventionalized figures of animals and humans occur, as well as signs. Representations of footprints are especially noticeable among the engravings. The paintings occur in rock-shelters, the engravings on open rock surfaces. Among the illustrations given is a number of excellent photographic reproductions. So much has been done recently to render available to students this interesting native Australian art that one wonders when the various investigators, headed by Mr. MeCarthy, will get together to produce a really worthy, well-illustrated volume on the subject. Museum articles and the like are all very well, but not everyone outside Australia can easily put their hands on them. It is time a more complete account appeared.

\section{The Whaley Skull}

As interesting excavation was undertaken in Derbyshire by the late Leslie Armstrong, in company with the late Dr. Arthur Court, at the Whaley rockshelter, not many miles from the more classic palæolithic sites at Creswell Crags. The work started so long ago as 1938, but the well-known skull was only unearthed in 1947. A number of archæological levels was identified, ranging from two Mousterian layers at the bottom to Aurignacian and proto-Solutrean levels above. Between the two series there was a sterile layer. The Whaley skull appeared to be a deliberate burial in the proto-Solutrean layer. Associated with it in the level were antler, bone and flint tools typical of the culture. The skull was buried with the base downwards and the frontal parts facing the wall of the shelter. Dr. Oakley has examined the chemical composition of the skull and the results obtained are in no way inconsistent with it being of Upper Palæolithic date, though from the point of viow of the measurements of the skull itself it could almost equally be of a female of Neolithic date. In an article in Man of July 1961 , D. R. Brothwell, of the Duckworth Laboratory of Physical Anthropology at Cambridge, describes the find in detail with comparative data from other sites. It seems likely that a proto-Solutrean family living in this rock-shelter carefully buried the skull of a woman who was fully adult, though the original suggestion that she was about fifty years of age now seems doubtful; but why she was carefully buried in the 'home' will never be known.

\section{Natural Rubber Producers' Research Association}

THe annual report of the Natural Rubber Producers' Research Association once more directs attention to the steady development of the natural rubber industry in the face of ever-growing competition from a variety of synthetics. Latest among these is the cis-1 : 4-polyisoprene rubber, which, for the first time, actually reproduces the essential structure of the natural rubber molecule, and which, with the closely allied cis-1:4-polybutadiene, is likely to prove a formidable challenge. This challenge is being met by concentration on improved efficiency in production and marketing, and by the continuous application of fundamental research. Among the more striking of the fundamental researches referred to is the discovery that the immediate precursor of the rubber hydrocarbon in the rubber plant is isopentenyl pyrophosphate. This substance has 